EDITORIAL

\title{
Neurodevelopmental processes in the ontogenesis and epigenesis of psychopathology
}

\author{
DANTE CICCHETTI ${ }^{a}$ AND TYRONE D. CANNON ${ }^{b}$ \\ ${ }^{a}$ Mt. Hope Family Center, University of Rochester; and ${ }^{b}$ University of California at \\ Los Angeles
}

\begin{abstract}
Dramatic gains in knowledge have been made in the fields of neuroscience, human development, and developmental psychopathology during the past quarter of a century. Despite the advances that have been achieved in each discipline separately, considerably less progress has occurred in understanding the relation between neurobiological and behavioral development in normal and atypical populations. Research has increasingly demonstrated that abnormalities that occur early in development may result in the emergence of aberrant neural circuitry that eventuates in relatively enduring forms of psychopathology. Knowledge of normal neurobiological development provides a powerful foundation for understanding the contributions that neurodevelopmental processes make to the etiology and sequelae of psychopathology across the life course. An integrated perspective wherein an appreciation of the complex neural, psychological, and social-contextual processes that cohere to bring about normal and pathological outcomes is necessary in order to advance understanding of the genesis and epigenesis of mental disorders. Such an approach will require a reduction of the schisms that so often separate neurobiological and behavioral research.
\end{abstract}

During the past quarter of a century, dramatic knowledge gains have been achieved in the fields of neuroscience, human development, and developmental psychopathology (see, e.g., Alberts, Bray, Lewis, Raff, Roberts, \& Watson, 1994; Cicchetti \& Cohen, 1995a,

We acknowledge the seminal influences of our respective mentors, Paul E. Meehl and Sarnoff A. Mednick. Dante Cicchetti's work on this manuscript was supported, in part, by grants from the National Institute of Mental Health (MH 54643), the Administration on Children, Youth, and Families, and the Spunk Fund, Inc. Tyrone Cannon's work on this manuscript was supported, in part, by grants from the National Institute of Mental Health (MH 52857), the March of Dimes Birth Defects Foundation, the Stanley Research Foundation, and the National Alliance for Research on Schizophrenia and Depression (NARSAD).

Address correspondence and reprint requests to: Dante Cicchetti, Mt. Hope Family Center, 187 Edinburgh Street, Rochester, NY 14608. 1995b; Damon, 1998; Edelman, 1987; Gazzaniga, 1995; Nowakowski \& Hayes, 1999; Rakic, 1988; Sapolsky, 1992; Sidman \& Rakic, 1982). Unfortunately, despite the advances that have occurred in each discipline separately, understanding of the nature of the relation between neurobiological and behavioral growth in normal and atypical populations across the life course remains in a relatively primitive state.

An examination of the history of developmental psychology reveals that, despite the influence that embryologists such as Waddington (1957) and Weiss (1969) exerted upon the leading systematizers in the field of human development (Cicchetti, 1990), the majority of the classic developmental theories did not accord much importance to the understanding of the brain and its pattern of neurobiological growth (Johnson, 1998; Segalowitz, 1994). 
Undoubtedly, the relative neglect of developmental neurobiology as relevant to the field of developmental psychology was due, in part, to the paucity of information that existed about the structural and functional organization of the brain (Dorovini-Zis \& Doman, 1977; Goldman-Rakic, 1987; Johnson, 1998; Kandel, 1998, 1999). Moreover, most of the prevailing views of the relation between neurobiological development and change in other ontogenetic domains (e.g., cognitive, socioemotional, and linguistic growth), in both normality and pathology, were linear and "main effects" in nature (Cicchetti, 1984; Johnson, 1993; Reese \& Overton, 1970; Sameroff \& Chandler, 1975).

For example, evidence linking change at the level of behavior in a given domain with development at the neural level was often construed as causal evidence for that change being due to maturation of the brain, a unidirectional, nondynamic view of brain-behavior relations (Cicchetti \& Tucker, 1994a, 1994b; Johnson, 1993; Thelen \& Smith, 1998). Likewise, in studies that were the forerunners of modern day prospective longitudinal studies on neurodevelopmental processes, terms such as the "continuum of reproductive wastage" (Lilienfeld \& Parkhurst, 1951) and the "continuum of reproductive casualty" (Pasamanick \& Knobloch, 1961) were used to explain findings demonstrating the retrospective links between pathological outcomes in children and adults and prior prenatal and perinatal complications. Despite the methodological shortcomings inherent in the retrospective method employed, causal power was imputed to biological factors in explaining the pathways to the problematic functioning displayed by the children and adults. It is quite conceivable that for many scientists such deterministic and reductionistic models of biological causality may have discouraged the search for the developmental processes, as well as the direction of causality, underlying the links between neural and behavioral development across epigenesis.

In recent decades, it has become increasingly recognized that the investigation of developmental processes, normal and abnormal, is an inherently interdisciplinary enterprise
(Cicchetti, 1984, 1993; Gottlieb, Wahlsten, \& Lickliter, 1998; Thelen \& Smith, 1998). Different levels and methods of analysis must be employed (e.g., molecular, cellular, behavioral, and macrosystem levels), depending on the question being addressed (Gottlieb, 1992; Johnson, 1998; Nelson \& Bloom, 1997). Neuroscientists increasingly have changed their emphasis from investigating molecules, membranes, and single neurons to studying complex neural systems (Crick, 1994; Damasio, 1994; Edelman, 1987; Thelen \& Smith, 1994). In these more contemporary conceptualizations of brain-behavior relations, the brain is viewed as operating in a plastic, selforganizing fashion, and as being less constrained by predetermined boundaries than previously thought. Consequently, information in the brain is represented and processed by distributed groups of neurons that maintain a functional interconnection based on experiential demands rather than by a strictly predetermined scheme (Courchesne, Chisum, \& Townsend, 1994; Gottlieb et al., 1998; Johnson, 1998; Thelen \& Smith, 1998).

One prominent developmental-systems viewpoint, that of the psychobiologist Gottlieb (1991), depicts individual development as characterized by "an increase of complexity of organization ... at all levels of analysis ... as a consequence of horizontal and vertical coactions among the organisms' parts, including organism-environment coactions" ( $\mathrm{p}$. 7). According to Gottlieb (1992), horizontal coactions take place at the same level of analysis (e.g., gene-gene, cell-cell, person-person, environment-environment), whereas vertical coactions occur at a different level of analysis (e.g., cell-tissue, organism-environment, behavioral activity-nervous system) and are reciprocal. As such, and in keeping with Weiss' (1959) notion of the hierarchy of reciprocal influences, vertical coactions are capable of influencing developmental organization from either lower-to-higher (i.e., bottom-up) or higher-to-lower (i.e., top-down; cf. Cicchetti \& Tucker, 1994a, 1994b) levels of the developing system (Gottlieb, 1992). Accordingly, from this framework, not only can neural/biological factors impact upon psychological processes, but also psychological and 
social experiences can modify the structure, function, and organization of the brain, as well as effect gene expression (Cicchetti \& Tucker, 1994a, 1994b; Dawson, Hessl, \& Frey, 1994; Eisenberg, 1995; Graham, Heim, Goodman, Miller, \& Nemeroff, 1999; Johnson, 1993; Kandel, 1998; Nelson \& Bloom, 1997; Sutcliffe, Milner, Gottesfeld, \& Reynolds, 1984). Thus, epigenesis is viewed as probabilistic rather than predetermined or preformational, with the bidirectional and transactional nature of genetic, neural, behavioral, and environmental influence over the life course capturing the essence of probabilistic epigenesis.

As is apparent, systems views of brain-behavior relations are multidimensional. Therefore, no component, subsystem, or level of organization possesses causal privilege in the developmental system (Thelen \& Smith, 1994, 1998). Because levels of organization and processes are reciprocally interactive, it is difficult, if not impossible, to impute ultimate causation to one level over another. No single level of the system or single component of a coaction can cause development. It is the mutual relationship between at least two components of the system that influences developmental organization (Gottlieb, 1992). In contrast to the linear and unidirectional view inherent in concepts such as the "continuum of reproductive casualty," prospective longitudinal research reveals that a bidirectional, transactional, systems theory view that combines the "continuum of reproductive casualty" with the "continuum of caretaking casualty" best captures the essence of the relations between neural and environmental/behavioral events over the life course (see Sameroff \& Chandler, 1975).

Such a perspective leads to the realization that, in order to formulate a comprehensive understanding of normal and abnormal developmental processes, it is essential to examine biological, psychological, and social factors within the same individuals over developmental time. A corollary is that although biological and genetic factors are not accorded privileged causal status in developmental systems approaches, theoretical and empirical work in developmental psychology and psy- chopathology nonetheless cannot afford to overlook the contribution that neurodevelopmental processes can make to normal and pathological outcomes.

In recent decades, important technological advances have occurred that greatly enhance the ability of neuroscientists to discover normal and pathologic processes in the nervous system (Kandel, 1998; Nelson \& Bloom, 1997). A rapid growth in sophisticated techniques that permit anatomical and physiological imaging of the brain has taken place. The new tools that neuroscientists can utilize to permit detailed examination of brain structure and function include magnetic resonance imaging (MRI), functional MRI (fMRI), positron emission tomography (PET), and single-photon emission-computed tomography (SPECT; for a description of the advantages and disadvantages of these respective techniques, see Brown \& Semelka, 1995; Cannon et al., 1998; Chugani, Phelps, \& Mazziotta, 1987; Gilman, 1998a, 1998b; Nahas, George, Lorberbaum, Risch, \& Spicer, 1998; Thatcher, Hallett, Zeffiro, John, \& Huerta, 1994; Thatcher, Lyon, Rumsey, \& Krasnegor, 1996; and Toga \& Mazziotta, 1996). Diverse information about the brain is provided by these various imaging techniques, including brain metabolic processes, such as cerebral blood flow and blood volume, and glucose metabolic rate; the capacity to distinguish among cerebrospinal fluid (CSF) and white and gray matter; and the ability to detect biochemical changes within brain cells, such as changes in neurotransmitter receptors. These new neuroimaging methods have been used by neuroscientists to enhance our understanding of normal and abnormal neurobiological development and of the processes linking neurodevelopmental factors and later disordered outcomes.

\section{Principles of Developmental Neuroscience and Developmental Psychopathology}

One of the basic principles of the field of developmental psychopathology-namely, that the study of normality and pathology are mutually enriching (Cicchetti, 1984, 1990, 1993) - also is embraced by developmental neuroscientists. For example, Johnson (1998) 
contends that understanding the nature of the relation between brain development and cognitive growth will be beneficial to clinicians who treat disordered patients. Likewise, Goldman-Rakic (1987) conjectured that "knowledge of the normal sequence and mechanisms of neural maturation is necessary for approaching many basic issues in ... developmental psychology" (p. 602). She opined further that knowledge of normal neurobiological development also was "fundamental for interpreting the pathological processes that occur ... in severe ... disorders" (p. 602).

Additionally, researchers investigating neurodevelopmental processes in biological and psychological dysfunction also recognize the important contributions that knowledge of normal neurobiological development makes to understanding disordered outcomes. For example, Arnold (1999), Nowakowski (1987; Nowakowski \& Hayes, 1999), Cannon (1998), and Pennington (1999) all contend that it is necessary to understand the processes and patterns of normal cerebral development in order to have a sound base for embarking upon, and interpreting the results of, studies of neurodevelopmental pathology. Similarly, Weinberger (1987, 1995; Breslin \& Weinberger, 1990) and Benes (1995) have noted that in order to comprehend the changes that unfold in the clinical presentation of schizophrenic patients over epigenesis, it is critical to realize that these deviations occur, in part, because of variations that occur in the normal progression of the anatomical, physiological, and functional maturation of the brain (see also Nowakowski \& Hayes, 1999).

Likewise, developmental psychopathologists have long argued that one gains valuable information about an organism's normal functioning through studying its abnormal condition (see Cicchetti, 1990, for a historical review). Accordingly, developmental theories can be affirmed, challenged, and augmented by incorporating knowledge about atypical development. Specifically, the examination of individuals with high-risk conditions and mental disorders can provide a natural entree into the study of system organization, disorganization, and reorganization that is otherwise not possible due to the constraints associated with research involving human participants. Similar to genetic research on pathological embryos, investigations of the factors that cause development to go awry inform our understanding of more normative developmental processes. Through studying a variety of disordered and high-risk conditions, it is possible to gain significant insight into processes of development not generally achieved through sole reliance on investigations of relatively homogeneous nondisordered populations. Moreover, research on atypical populations also can elucidate the behavioral and biological consequences of alternate pathways of development, provide important information about the range and variability of individual response to challenge and adversity, and help to specify the limits of behavioral and biological plasticity (Cicchetti, 1996; Johnson, 1998; Luthar, Cicchetti, \& Becker, in press).

For nearly a century, Cajal's (1913) assertion that in "adult centers the nerve paths are something fixed, ended, immutable. Everything may die, nothing may be regenerated" (p. 750) served as the prevailing dogma about the brain's inability to regenerate following injury or in response to the neuronal loss that occurs in neurodegenerative diseases (Lowenstein \& Parent, 1999). The conventional wisdom until recently was that, since no new neuron generation was deemed possible, rewiring of existing connections, dendritic branching, and elimination of synaptic connections were the only ways whereby neural plasticity could occur. As Pennington (1999) elucidates, the early neuropsychological models of the effects of brain lesions were based on work with patients and were predominantly focused on localization and unidirectional models of causality (i.e., brain lesions were thought to affect behavior). These early models did not take into account the dynamic interplay that occurs among brain regions and the bidirectional impact that brain-behavior relations exert upon each other. Modern-day research provides suggestive evidence that the mammalian central nervous system possesses much greater potential for producing new neurons and repairing damaged areas than had heretofore been thought (Cicchetti \& Tucker, 1994b; Hann, Huffman, Lederhendler, \& 
Meinecke, 1998; Johnson, 1998; Lowenstein \& Parent, 1999).

Whereas historically recovery of function following brain damage had been believed to occur only if the lesion had occurred early in development (i.e., the Kennard principle), contemporary neurobiological and neuropsychological evidence suggests that plasticity is an inherent property of at least some brain structures (Johnson, 1998). It is now recognized that the mechanisms supporting functional plasticity are integral to neurons, and that these mechanisms cause the functional organization of the brain to be an extended, malleable process. Further, it is believed that the discovery of the mechanisms that constrain plasticity will present neuroscientists with new avenues for understanding the contributions that vulnerability of the brain makes to the development of psychopathology (Cannon, 1998; Cicchetti \& Tucker, 1994a, 1994b; Nelson \& Bloom, 1997). The neurophysiological mechanisms of plasticity cause the brain's functional-organizational differentiation to be dependent on stimulation from the environment. In contrast to the traditional assumption that the environment determines only the psychological residuals of development and that brain anatomy matures on a fixed ontogenetic calendar, environmental experience is currently conceived as being essential to the processes underlying the functional differentiation of brain tissue itself (Cicchetti \& Tucker, 1994a; Greenough, Black, \& Wallace, 1987). For example, although no prospective longitudinal studies of maltreated infants have been conducted that link early neurodevelopmental processes and later biological and psychological functioning, there is suggestive evidence that early maltreatment experiences may alter brain structure, function, and organization, especially in, but not restricted to, the hippocampus (Bremner \& Narayan, 1998; Cicchetti \& Tucker, 1994a; DeBellis et al., 1999; Graham, et al., 1999; Gurvits, Shenton, Hokama, Ohta, Lasko, Gilbertson, Orr, Kikinis, Jolesz, McCarley, \& Pitman, 1996; McEwen \& Sapolsky, 1995; Perry, Pollard, Blakley, Baker, \& Vigilante, 1995; Pollak, Cicchetti, Klorman, \& Brumaghim, 1997).
During the past several decades, scientific research has begun to reveal that within certain limits, forms of neural plasticity may take place throughout epigenesis and are not limited to early development (Cicchetti \& Tucker, 1994b; Hann et al., 1998). In the developing organism, studies conducted with a variety of species have revealed that positive or negative early life experiences can change both brain structure and function (Eisenberg, 1995; Hann et al., 1998; Kandel, 1999; McEwen \& Sapolsky, 1995; Meaney, Aitken, \& Sapolsky, 1991; Nelson \& Bloom, 1997; Sapolsky, 1992). For example, Sur and colleagues (Sur, Garraghty, \& Roe, 1988; Sur, Pallas, \& Roe, 1990) trained adult ferrets, who had one hemisphere rewired at birth, to discriminate between auditory and visual stimuli that were presented to the normal hemisphere. The results of these experiments provide support for the functional equipotentiality of cortical mapping. Specifically, the findings in the Sur et al. $(1988,1990)$ investigations demonstrate that it is possible to rewire sensory inputs to the thalamus such that processing of auditory stimuli takes place in primary visual cortex and vice versa; that is, the cortical field that usually mediates vision could attain a functional organization capable of processing sound, and the cortical field that usually mediates audition could attain a functional organization capable of processing sight.

In addition, Kempermann, Kuhn, and Gage (1998) found that neurogenesis continues to occur in the dentate gyrus of senescent mice and can be stimulated when the mice are placed in an enriched environment. Kempermann and colleagues found that neurogenesis decreased with increasing age; however, stimulation of adult and aged mice by changing from regular housing to an enriched environment that provided opportunities for social interaction, physical activity, and exploration brought about an increased number of survival cells. Further, animals living in enriched environments had more of their cells differentiate into neurons than did mice residing in standard conditions. These findings suggest that the new neurons were recruited in the hippocampal area and that neural plasticity can take place in the aging brain in mice. 
Likewise, Gould, Tarapat, McEwen, Flugge, and Fuchs (1998) found that new neurons are produced in the dentate gyrus of adult monkeys. Moreover, these investigators discovered that a single exposure to a socially stressful condition (i.e., a resident-intruder unfamiliar adult male conspecific) inhibits the proliferation of granule cell precursors. Taken together with the results of other studies with rats, tree shrews, primates, and humans, it seems clear that granule neurons in the hippocampus are commonly produced during adulthood and that their inhibition by stressful social experiences may occur frequently in many species, including humans (Bremner \& Narayan, 1998; McEwen, 1998; McEwen \& Stellar, 1993). Unlike longstanding views on neural plasticity, empirical evidence demonstrates that new neuron generation can take place in mice, primates, and humans, at least in the dentate gyrus in the hippocampus. Cortisol and glucocorticoids control the rate of the development of these new neurons, and it is clear that the existing neurons are not merely reorganizing their connections. It remains to be discovered which other brain regions are capable of such plasticity and to determine what limits to neural plasticity exist.

The long held assumption that neural reorganization following injury was restricted to the period of infancy, with only modest neural reorganization possible in the child and adult, has been challenged through recent research with humans. Results from a number of investigations suggest that reorganization of cortical pathways can occur in the brains of older children and adults (Merzenich, 1998; Merzenich, Jenkins, Johnson, Schreiner, Miller, \& Tallal, 1996; Tallal et al., 1996). Although the majority of these neural changes to date have been demonstrated in work on sensory or motor pathways (see, e.g., Aglioti, Bonazzi, \& Cortese, 1994), recent work provides suggestive evidence that cognitive systems (i.e., language) can reorganize beyond infancy (see, e.g., Merzenich et al., 1996; Tallal, et al. 1996; see also discussions in Johnson, 1999). Thus, it is now clear that under certain conditions at least some regions of the brain can incorporate the signature of experience into the structure and function of the brain.
The normally developing neural network is characterized by a self-constructing, continuous, rapid, and marked change from one involving fewer elements and interactions among the elements, less stability, and less structural and functional differentiation to one characterized by more elements, increased complexity of interactions among the elements, greater stability, and more structural and functional parcellation and specialization (Conel, 1939-1967; Courchesne, Townsend, \& Chase, 1995; Dawson \& Fischer, 1994; Frackowiak, Friston, Frith, Dolan, \& Mazziotta, 1997; Rakic, 1988, 1995; Sidman \& Rakic, 1973 , 1982). As a result of the dynamic process of the emergence, transformation, and selective elimination of neurons, axons, and synapses (Cowan, Fawcett, O'Leary, \& Stanfield, 1984; Edelman, 1987; Fischer \& Rose, 1996; Huttenlocher, 1979), successively more complex, specialized, and stable neural network configurations develop that differ considerably from antecedent ones. Perturbations that take place in the developing brain can trigger a cascade of growth and function changes that lead the neural system down a path that deviates from that usually taken in normal neurobiological development. As many of the papers in this Special Issue illustrate, such early developmental abnormalities may lead to the development of aberrant neural circuitry and often compound themselves into relatively enduring forms of psychopathology.

\section{Neurodevelopment and Psychopathology}

The principles that contemporary developmental neuroscientists have discovered can be utilized to inform research on psychopathology that includes a neurodevelopmental component. It appears that the processes of the development of the brain during the embryonic, infancy, childhood, and adulthood periods have many principles and neurobiological mechanisms at the level of gene expression in common (Brown, 1994; Kandel, 1998; Nowakowski, 1987; Nowakowski \& Hayes, 1999; Sidman \& Rakic, 1982). Moreover, now that it is evident that experience can impact on the microstructure and biochemistry of the brain, 
a vital role for very early and continuing neural plasticity throughout epigenesis in contributing to the development of, and recovery from, various forms of psychopathology is suggested.

Much of the modern-day research in the area of neurodevelopment and psychopathology owes a significant portion of its historical roots to the original formulations of Kraepelin (1919), who conceived of schizophrenia as a deteriorating brain disease, akin to Alzheimer's disease in its natural history, albeit with an onset in early adult life. Since the 1980s, when there was a renewed interest in biological studies of schizophrenia, Kraepelin's (1919) view has been challenged and radically changed by advances from several levels of inquiry that point to a prenatal-perinatal origin of at least some of the brain abnormalities in schizophrenia (Cannon, 1998; Keshavan \& Murray, 1997; McNeil, 1988; Mednick, Cannon, Barr, \& LaFosse, 1991; Mednick, Cannon, Barr, \& Lyon, 1991; Mednick \& Hollister, 1995). Mednick's seminal early work (see, e.g., Mednick, 1970; Mednick, Machon, Huttunen, \& Bonett, 1988) paved the way for viewing schizophrenia as resulting, in part, from prenatal disturbances.

Similarly, prospective longitudinal highrisk studies have revealed that behavioral antecedents of schizophrenia occurred before the disease. For example, influenced by Meehl's (1962; see also 1989) classic notion that schizotaxia was an inherited neurointegrative defect that could develop in the presence of polygenic potentiators into full-blown clinical schizophrenia, Fish (1977) demonstrated that a neurobiologic disorder exists in infants and children prior to the onset of more chronic forms of schizophrenia. Fish's (1977) discovery of pandevelopmental retardation was an early marker of the neurointegrative defect postulated to exist in schizophrenia by Meehl (1962).

Importantly, Fish (1977) noted that the phenotypic manifestations of the neurointegrative defect change over developmental time and that the signs of dysregulation of maturation are found in many developing systems. Specifically, Fish (1977) reported that the neurointegrative disorder present from in- fancy disrupted the normal timing, sequence, and overall organization of development. In essence, Fish (1977) had uncovered an early neurointegrative disorder, thought to be a precursor of later schizophrenia, that impaired the overall regulation and patterning of the total organization of the developmental process.

In a landmark prospective longitudinal investigation, Fish, Marcus, Hans, Auerbach, and Perdue (1992) discovered that the infant offspring of schizophrenic mothers displayed greater lags in their motor development during infancy and that a number of these infants themselves went on to develop schizophrenia or schizotypal personality disorders. Relatedly, in a seminal retrospective study, Walker, Savoie, and Davis (1994) analyzed the childhood home movies of adult-onset schizophrenic patients during the first 2 years of life and found that, as infants, the schizophrenics manifested a significant number of motor delays and movement anomalies compared to their healthy siblings and a control group with mood disorders.

In addition to the early and more recent work with preschizophrenic infants that served as an impetus for modifying the Kraepelinian (1919) view of schizophrenia, modern-day findings have contributed to the belief that the neurobiological foundations of schizophrenia are established, at least in part, during the development of the brain. These include the following:

1. Several prospective longitudinal investigations have discovered an association between prenatal and perinatal complications (e.g., fetal hypoxia) and an increased risk for the later development of schizophrenia (Cannon, 1998; Lyon, Barr, Cannon, Mednick, \& Shore, 1989). These results suggest that the adverse effects of obstetric complications on the developing fetal brain may play a role in the etiology of schizophrenia.

2. A number of postmortem neuropathology studies have found evidence of displacement of neurons in various regions of the brain, including the hippocampus and the frontal and temporal cortices. These findings suggest that there are disturbances of 
brain development in utero in many schizophrenics (see Arnold, 1999; see also Nowakowski \& Hayes, 1999).

3. A growing body of neuroimaging studies has identified gross structural neuroanatomy changes in young, untreated patients in their first psychotic episode. Further, and in contrast to a Kraepelinian (1919) neurodegenerative viewpoint, these investigations have failed to discover evidence of deterioration in these neuropathological markers with increasing length of the illness.

4. A number of the unaffected first-degree relatives of schizophrenic patients manifest the structural and functional brain abnormalities observed in schizophrenics, implying that such abnormalities may be mediated, in part, by genetic predisposition to the disorder (Cannon, Mednick, Parnas, Schulsinger, Praestholm, \& Vestergaard, 1993; Cannon, Mednick, Schulsinger, Parnas, Praestholm, \& Vestergaard, 1994).

5. Prospective longitudinal studies of highrisk samples (such as the offspring of schizophrenic parents) and representative birth cohorts have demonstrated that future schizophrenic patients reveal neuromotor impairment and cognitive dysfunction during infancy and childhood (Cannon, Rosso, Bearden, Sanchez, \& Hadley, 1999; Walker, 1994). These data provide suggestive evidence that the early development of the brain in schizophrenics is disrupted, thereby precluding the ontogenesis of normal cerebral structure and function.

Importantly, the extant models linking neurodevelopment and schizophrenia point to a nonlinearity of relations. There is a long latency between the gestational events hypothesized to create a predisposition to schizophrenia and the onset of the symptoms of the disorder later in life. Longitudinal follow-up of individuals who have experienced traumatic insults to the brain at early stages of development, such as is likely the case in many instances of schizophrenia, enables investigators to chart and observe the changing expression of these early lesions as development modifies behavior in general. Alternatively, for some individuals it also is conceivable that the lesion directly effects later developmental processes via cascade, propagation, and expansion (Cicchetti \& Tucker, 1994a; Post, Weiss, \& Leverich, 1994). These options all provide an opportunity to discover how brain and behavior reorganize following the experience of insults at different points in the developmental course (Johnson, 1999; Nowakowski \& Hayes, 1999).

Because not all individuals who experience the gestational disturbances noted in the literature go on to develop clinical schizophrenia, the concept of probabilistic epigenesis is evoked (Gottlieb, 1992; Johnson, 1999), whereby the relations between brain and behavioral development are conceived as existing in a dynamic, bidirectional relation. In addition, the existing research reveals that there are a number of pathways through which the early neurodevelopmental abnormalities may eventuate in schizophrenia. The identification of these diverse pathways to schizophrenia provides insight into how specificity and differentiation into a syndrome may result from a commonality of initiating circumstances. These multiple pathways, reflective of the systems theory concept of equifinality (Cicchetti \& Rogosch, 1996; Gottlieb et al., 1998), embrace a number of possible contributors which may potentiate or mediate the links between early neurodevelopmental anomalies and schizophrenia in genetically vulnerable individuals. These include the normal developmental changes that take place during late adolescence and early adulthood (e.g., cell elimination; Cowan, Fawcett, O'Leary, \& Stanfield, 1984; Feinberg, 1982; Keshavan, Anderson, \& Pettegrew, 1994), hormonal changes during adolescence, and stress that arises during postnatal social development (Cannon, 1998; Keshavan \& Hogarty, 1999; Walker et al., 1999).

As Cannon (1998) has noted, to date no study has shown a direct link between a molecular or cellular event during the development of the brain to the etiology of schizophrenia. Consequently, the evidence of schizophrenia as a disorder of neurodevelop- 
ment remains circumstantial. An alternative, and not necessarily mutually exclusive, account of the data may be that the neuropathological anomalies reflect a brain that was initially normal but that later encountered some pathological process, concomitant with or preceding the onset of psychosis. Nonetheless, if there is a dementia-like deterioration in the brain of individuals with schizophrenia, then it is not like those observed in known disorders of dementia. Specifically, markers of neuronal atrophy are not prominent and the rate of tissue loss is so slight as not to be detectable in the majority of investigations (Arnold, 1999; Cannon, 1998). A confluence of findings emanating from a number of research laboratories provides suggestive evidence that the processes underlying the normal development and maturation of cortical circuitry and connectivity have gone awry in schizophrenia (Arnold, 1999; Benes, 1995; Weinberger, 1987, 1995). Unraveling these misorganizations in brain development should contribute greatly to understanding the ontogenesis of schizophrenic disorders.

\section{The Current Issue}

The papers in this Special Issue provide illustrations of how the broad neurodevelopmental principles derived from basic research in modern-day neuroscience elucidate the understanding of the development of psychopathology over the course of epigenesis (Nowakowski \& Hayes, 1999; Johnson, 1999). Drawing upon historical and contemporary bases of research, a number of the contributors to this Special Issue have provided synthetic reviews, theoretical expositions, or empirical investigations pertaining to the neurodevelopmental aspects of psychopathology and developmental disorders. Each of the contributors addresses multiple domains and several utilize varied levels of analysis.

Arnold (1999) provides a careful and thorough review of the neuropathology literature and concludes that abnormalities in neurobiological development play a critical role in the ontogenesis and epigenesis of schizophrenia. Disturbances in neurogenesis, neuronal migration and differentiation, synaptogenesis, neuron and synaptic pruning, and myelination, occurring at the cellular and molecular levels, suggest that schizophrenia is a disorder that is instantiated in brain development.

As noted earlier, Mednick's classic work on the neurodevelopmental aspects of schizophrenia was a pioneering effort in the area of neurodevelopment and psychopathology. Herein, Watson, Mednick, Huttunen, and Wang (1999) present evidence from several large-scale investigations that prenatal teratogens may increase the risk for adult schizophrenia and affective disorder, as well as for adolescent depression. Specifically, Watson and colleagues (1999) found that a 2nd-trimester maternal influenza infection may exacerbate the risk for adult schizophrenia and affective disorder, whereas exposure prenatally to a severe earthquake contributed to an increased frequency of severe adolescent depression in males.

These investigators interpret their findings as indicating that maternal influenza infection and severe maternal stress operate via different mechanisms as teratogens, causing disruptions in fetal brain development at different points in prenatal gestation and increasing the risk for developing schizophrenia and affective disorder, respectively. In particular, as Rakic (1988), Sidman and Rakic (1973, 1982), and Nowakowski (1987; Nowakowski \& Hayes, 1999) have demonstrated, during periods of rapid brain development in which neuronal migration is occurring and synaptic connections are formed, the fetal brain is especially vulnerable. Exogenous teratogens, such as maternal influenza and exposure to earthquakes, may exert dramatic effects on the regions of the brain experiencing the most rapid growth. Introducing these teratogens also may place the cortical connections being established and refined at increased risk for aberrant development. Further, with respect to the stress of exposure to an earthquake while in utero, Watson and colleagues (1999) conjecture that the earthquake likely elevated the release of glucocorticoids in the pregnant women and that this elevation may have exerted a deleterious effect on the fetuses' developing hypothalamic-pituitaryadrenal (HPA) axis and/or glucocorticoid 
receptors. Finally, in a recognition of the complexity underlying the developmental pathways to schizophrenia, the investigators acknowledge that additional factors such as genetic predisposition, obstetrical complications, and family environment play an important role in the development of mental illness.

In a related vein, Cannon, Rosso, Bearden, Sanchez, and Hadley (1999), in their epidemiological investigation of the Philadelphia cohort of the National Collaborative Perinatal Project (Niswader \& Gordon, 1972), proffer compelling evidence that adverse experiences during gestation and birth, as well as deviant cognitive, motor, and behavioral functioning during early childhood, are associated with an increased risk for schizophrenia. In particular, they show that the risk for schizophrenia increases linearly with the severity (or likelihood) of fetal oxygen deprivation. In prior neuroimaging studies of high-risk samples conducted by this group, a history of perinatal hypoxia was found to be associated with increased severity of a neuropathological indicator of schizophrenia (i.e., ventricular enlargement) among individuals with an elevated genetic risk for the disorder, but not among controls at low genetic risk (Cannon, Mednick, Parnas, Schulsinger, Praestholm \& Vestergaard, 1993; Cannon, van Erp, Huttunen, Lonnqvist, Salonen, Valanne, Poutanen \& Standerskjold-Nordenstam, in review). Together, this evidence suggests that a genetic factor in schizophrenia may render the fetal brain particularly susceptible to the effects of oxygen deprivation and encourages search for molecular mechanisms underlying this heightened neural vulnerability.

Cannon et al. (1999) also find that preschizophrenic individuals show evidence of cognitive, motor, and behavioral dysfunction during the first 7 years of life. Because there was not evidence of significant intraindividual decline during this period within any domain of functioning, the results argue against the view that a deteriorative neural process underlies these early phenotypic expressions of liability to schizophrenia. Rather, the results suggest that an increasing number of diverse phenotypic signs emerge with age as the diverse brain systems required for their expres- sion reach functional maturity. Finally, because similar functional disturbances were observed in the unaffected siblings of the preschizophrenic cases, it would appear that these cognitive, motor, and behavioral disturbances are indicators of an inherited neural diathesis to schizophrenia.

Cornblatt, Obuchowski, Roberts, Pollack, and Erlenmeyer-Kimling (1999) examine the role of attentional deficits and behavioral maladjustment in the development of schizophrenic illness. Attentional and global behavioral data were collected at intervals over an approximate 15-year period (i.e., at specified points between 12 and 26 years) from offspring who were at high-risk (i.e., defined by the presence of one or two parents with the disorder of schizophrenia) and at low risk for schizophrenia. All participants were enrolled in the classic prospective longitudinal study, the New York High-Risk Project (Erlenmeyer-Kimling, Marcuse, Cornblatt, Friedman, Rainer, \& Rutschmann, 1984). Cornblatt and colleagues (1999) discovered that attentional anomalies can be identified reliably in high-risk children and adolescents who subsequently develop disorders in the schizophrenia spectrum. Moreover, these investigators found that the attentional deficits were stable and enduring over time and speculated that the impairments in attentional capacity are likely markers of a biological diathesis that is consistent with a neurodevelopmental view of schizophrenia.

Furthermore, there appear to be semi-independent developmental pathways for attention versus behavioral adjustment during the adolescent years. Specifically, in contrast to behavioral difficulties which are highly responsive to environmental stressors such as residing in turbulent households with one or more parents who have a serious mental disorder, attention does not seem to be affected by clinical state and impairments in the attentional domain appear to be clear indicators of a future mental illness for the adolescent, whereas preillness behavioral disturbances do not. Importantly, given the debilitating impact that schizophrenia exerts on the quality of life, Cornblatt and colleagues (1999) suggest that screening for attention and other neuro- 
cognitive deficits in late childhood may provide a reasonable strategy for primary prevention of the illness.

In an extension of the work of Fish (1977; Fish et al., 1992) and Walker et al. (1994), Walker, Lewis, Loewy, and Palyo (1999) study spontaneous motor movements in adolescents with schizotypal personality disorder (SPD), a syndrome that is known to be genetically linked with schizophrenia and that often predates the emergence of schizophrenia in early adulthood. Walker and colleagues (1994) discovered that adolescents with SPD manifested more involuntary, but not voluntary, movements of the head, upper limbs, and trunk than did adolescents with other personality disorders and normal adolescent comparisons. Additionally, adolescents with SPD displayed elevated cortisol (glucocorticoid) levels in comparison with the other two groups of adolescents. A number of aspects of these findings are especially noteworthy. First, the excess motor behavior was specific to involuntary movement and not merely a function of global activity level increases. Second, congruent with prior descriptions of schizophrenia patients, the increased involuntary movements were confined to the upper limbs and body. Third, involuntary movements and cortisol release may be risk markers for the later development of schizophrenia. Akin to the speculations of Cornblatt and colleagues (1999), perhaps the inclusion of adolescent involuntary motoric movement and the assessment of cortisol in a novel, laboratory situation should be a part of the neurocognitive screening battery for schizophrenia risk. At the biological level, Walker and colleagues (1999) note that there is evidence of functional interconnections among the motor, limbic, and prefrontal circuits that are presumed to be involved in the neuropathophysiology of schizophrenia and that these form a basis for integrating the motor, sensory, and motivational processes that characterize the disorder.

In a final illustration of neurodevelopmental processes that contribute to the development of schizophrenia in adolescence and early adulthood, Keshavan and Hogarty (1999) present a unified model, incorporating work on normative and abnormal brain development and plasticity, the roles of gonadal hormones and experience, neurotransmitter dysfunction and dysregulation, and the impact that social-cognitive development have on the adolescent's ability to deal effectively with environmental stress. Such an integrative, interdisciplinary model is necessary to capture the full complexity of schizophrenic illness, including the multiple pathways to, and the diverse outcomes associated with, the disorder. Keshavan and Hogarty (1999) contend that schizophrenia may result from genetic factors, early brain adversity, and late maturational processes of neurobiological development (e.g., synaptic and axonal pruning, synaptic elimination and axon myelination, and the prolonged development of neocortical association and limbic circuits until late adolescence) that interact in a complex fashion with humoral, biochemical, and social-cognitive factors during adolescence and early adulthood. Finally, Keshavan and Hogarty (1999) also suggest that specific treatments may be developed and implemented for use at particular developmental stages, pre-, post-, and during illness episodes.

Gillberg (1999) discusses how autistic individuals are not uniformly affected by their disorder. Moreover, he provides evidence that genetic and environmental insults to brain development play an important etiological role in autism and that there are two pathways to autism-one linked to early prenatal origins, the other to late prenatal and early postnatal origins. Furthermore, Gillberg concludes that the brain circuitries for communicative and social development, as well as for the integration of various developmental domains, are dysfunctional in autism. In keeping with the belief of developmental psychopathologists that the investigation of abnormality can inform the understanding of normal ontogenesis and epigenesis, Gillberg (1999) contends that the investigation of the neurodevelopmental and neuropsychological processes in autism will be useful in elucidating the mechanisms involved in normal neurobiological growth.

Graham and colleagues (1999) proffer support for the thesis that early adverse experiences contribute to affected individuals being 
more sensitive to the effects of stressors in later life. One outcome of this increased sensitivity to stress is that such individuals are rendered more vulnerable to psychopathology. Graham and colleagues (1999) suggest that this vulnerability may be mediated through persistent changes that occur in corticotrophin-releasing-factor (CRH)-containing neurons, the HPA axis, and the sympathetic nervous system. After reviewing the rodent, nonhuman-primate, and human literatures on the neurobiological and behavioral sequelae of exposure to early adversity, Graham and colleagues (1999) focus on animal models of depression and anxiety that produce neuroendocrine alterations mimicking those observed in adult humans with depressive and anxiety disorders. Likewise, these investigators discuss the effects of early stress on the neurobiological and behavioral development of maltreated youngsters and of the young offspring of mothers depressed during the postpartum period.

Disturbances in early caregiving are associated with neurobiological anomalies, as well as with later behavioral and emotional problems. Neurobiological adaptations to chronic or repeated stress may augment and support psychosocial processes associated with negative caregiving. Adverse life contexts, illustrated by the experience of child maltreatment and being raised by a depressed caregiver, affect both physiological and psychological processes, and the interrelation of these processes is believed to lead children to make choices and respond to experiences that promote pathological development (Cicchetti \& Toth, 1998). Early stresses, either biological or psychological, may sensitize young neural networks to produce cascading effects through later development, possibly constraining the child's flexibility to adapt to new challenging situations with new strategies rather than with old conceptual and behavioral prototypes (Cicchetti \& Tucker, 1994a).

Because children who are maltreated have been subjected to the extremes of caretaking casualty, they serve as an "experiment of nature" (cf. Johnson, 1999) for scientists to discover the various ways in which psychological stressors can affect biological systems. It is highly likely that numerous interconnected neurobiological systems are negatively affected by the various stressors associated with child maltreatment. Additionally, each of these neurobiological systems influences, and is influenced by, multiple domains of biological and psychological development (Cicchetti \& Toth, 1998). Further, repeated exposure to such adverse circumstances can alter brain development structure, function, and organization (Bremner \& Narayan, 1998; Cicchetti \& Tucker, 1994a; DeBellis et al., 1999; Gurvits et al., 1996). It is very important to ascertain whether, and when in development, interventions will be effective in modifying these neurobiological changes. Moreover, psychopharmacological treatments may help to stabilize the neurobiological systems that are dysregulated by maltreatment, thereby enabling cognitive or other psychological therapies to operate more effectively (Graham et al., 1999).

In a further demonstration of the effects of social experience on brain function, Dawson and colleagues (1999) found that the frontal electrical brain activity of infants of depressed mothers was related to variations in infant behavior, especially those involved in affiliative behavior and the expression and regulation of negative affect. The findings of Dawson and colleagues (1999), in concert with the results of other investigations that have discovered hemispheric activation asymmetries in infants of depressed mothers (see, e.g., Dawson, Grofer Klinger, Panagiotides, Hill, \& Spieker, 1992; Jones, Field, Fox, Lundy, \& Devalos, 1997), buttress the thesis that a mother's emotional condition (and implicitly her interaction with her baby) can impact developing patterns of neurogenesis and synaptogenesis in the early years of life. Convergence between biological and psychological systems is suggested, providing a window on the complexity of developmental organization that may heighten risk for depression.

Presently, little is known concerning the impact that maternal depression during the prenatal and early postpartum period has on fetal neurobiological and psychological development. The biochemical changes that are causes or correlates of the mother's depres- 
sive disorder, in concert with additional factors such as her sleep patterns, levels of stress, and nutrition, all likely contribute to a less than optimal intrauterine environment. Further, it is conceivable that these experiences in utero and during early postnatal development may impact upon the biochemistry and neuroanatomical structure, function, and organization of the developing brain of infants whose mothers have a major depressive disorder.

Taylor (1999) provides an integrative review of the research literature on the disorders of attention and activity. Taylor (1999) proposes several developmental pathways through which genetic and neurodevelopmental processes interact with the psychological environment en route to attentional or impulsive disorders. Taylor's (1999) analysis of the developmental processes in disorders of attention and activity focuses on multiple levels of causality. In addition to abnormalities of structure and function in the frontal lobe and basal ganglia, children with attention and impulsivity disorders often have problems in the suppression of inappropriate responses and a cascade of difficulties in various performance tasks that require the ability to utilize organizational skills. Furthermore, Taylor (1999) notes that some children escape the persistent problems of personality development commonly found as consequences of hyperactive behavior and develop as socially well-adjusted adults. Thus, Taylor (1999) argues for a complex view of the etiology (equifinality) and sequelae (multifinality) of disorders of attention and impulsivity.

Pennington (1999) likewise presents a critical review of the available evidence on developmental dyslexia. He, too, focuses on multiple levels of analysis: genetic, neurological, and cognitive. Pennington (1999) grapples with the difficulties inherent in establishing causal links between these levels of analysis, and concludes that it may be more difficult to solve the brain-behavior than the gene-behavior problem of causality.

Pennington (1999) further notes that investigations of dyslexia have contributed to the enhanced understanding of normal and abnormal cognitive processes. Additionally, Pen- nington (1999) advocates the importance of interdisciplinary communication and collaboration in the formulation of theories and methods that can combine the study of brain and behavior. The levels of analysis studied, as well as the nature of the questions posed, receive varying emphasis from the different disciplines who investigate brain and behavior in normality and pathology. A problem that must be solved involves how to foster increased integration among the various disciplinary approaches that are utilized in the study of brain-behavior relations.

\section{Conclusion and Future Perspective}

A major goal of this Special Issue is to illustrate how the study of neurodevelopmental processes can contribute to the understanding of the genesis and epigenesis of psychopathology. Knowledge of normal neurobiological development serves as the foundation for unraveling the contributions that neurodevelopmental processes make to the etiology and sequelae of psychopathology across the life course. Although the papers in this Special Issue do not cover everything that is known about neurodevelopment and disorder, through their focus on areas where we possess the most clear-cut knowledge the contributions can function as a heuristic for implementing and scaffolding future work on problems not addressed herein, as well as for further refining the issues with which the contributors have dealt.

Another objective of the Special Issue is to contribute to eroding the dualisms that exist between the behavioral and brain sciences. Theoretical and empirical evidence attests to the need for research to be conducted at multiple levels of inquiry in order to comprehend the etiology and developmental course of high-risk and psychopathological conditions. In recent decades, owing in part to technological advances and enhanced research funding, discoveries in the neurosciences have been growing at a rapid pace. However, even if advances in the behavioral sciences have not been as technologically dramatic as have those in the neurosciences, it is essential that knowledge obtained in biological research 
must be related to knowledge gained in behavioral research. Neither the neural nor the behavioral level is causally privileged. Thus, it is equally heinous to advocate a "brainless" psychology as it is to promote a "mindless" neuroscience.

In order to reduce the schisms that so often separate scientific research in different disciplines, it is important to remember Miller's (1995) assertion that "all of the different specialties-ranging from the basic to the applied and from the biological to the social and cultural-are needed to advance our common goal of better understanding human behavior" (p. 910). Along these lines, future graduate and medical school training must become increasingly interdisciplinary (Cicchetti \& Toth, 1991). Such an approach would help to prevent the development of disciplinary dogma and parochialism and foster an early appreciation of the complex processes-neural, psychological, and social-contextual-that cohere to bring about normal and pathological outcomes (Boyce et al., 1998; Cicchetti \& Aber, 1998). Concepts derived from extant systems theory viewpoints of brain-behavior relations, such as those utilized in the developmental cognitive neurosciences (Johnson, 1998; Thelen \& Smith, 1994), psychobiology (Gottlieb, 1992), and developmental psychopathology (Cicchetti \& Tucker, 1994a), can be used to develop curricula that ensure in-depth training and an ongoing respect for and encouragement of the interdisciplinary, multidomain perspective necessary to comprehend the genesis and epigenesis of mental disorders. Moreover, such a theory-driven training of future scientists will ensure that research is guided by pressing theoretical questions and not merely by advances in technology. The utilization of the theories and methods of cognitive neuroscience with brain imaging technology made possible by the computer revolution (e.g., fMRI) is but one example of a profitable collaboration between neuroscience and psychology within a theoretically grounded framework.

In order to achieve an integrative understanding of the nature of the links between neural processes and the genesis and epigenesis of various mental disorders and high-risk conditions, a number of tasks remain to be accomplished. There is a need for ongoing knowledge of the scientific advances generated in investigations of normal brain development. Research also is needed on the fundamental neural mechanisms involved in the development of various mental disorders, as well as molecular biological work on the structure and function of genes and proteins involved in neural proliferation, migration, and differentiation (Nowakowski \& Hayes, 1999). Likewise, neuroimaging studies should increasingly be conducted to uncover the integrated operation of distributed neural systems, and not merely the function of isolated structures. Even researchers focusing on similar levels of analysis must engage in interdisciplinary work in order to develop a thorough understanding of the question being investigated. Moreover, for example, schizophrenia researchers carrying out postmortem histopathological studies should collaborate with scientists who are investigating neurochemistry and combine research on anatomy and neurochemistry on the same brains (cf. Weinberger, 1987). Furthermore, many putative control subjects in studies investigating disability and psychopathology in childhood and adulthood have employed hospitalized nonpsychiatric patients as controls for their neurodevelopment research. If scientists examining the cellular and molecular levels of various high-risk conditions and mental disorders are going to succeed in their quest for identifying the neural mechanisms that affect brain function as well as the clinical manifestations of the various disorders examined, then it is essential to conduct neurodevelopmental studies, both postmortem and in vivo neuroimaging investigations, that utilize the brains of normal controls.

It also is apparent that future interdisciplinary work must increasingly be conducted in the context of prospective longitudinal research programs that not only investigate high-risk and mentally disordered individuals but also follow up well-matched normal comparisons over developmental time. Moreover, these multidomain, longitudinal investigations should endeavor to begin before a period of great developmental change takes place (e.g., 
for neurodevelopmental research on schizophrenia, the study should begin in the prenatal period), through the period when the onset of the disorder is at its highest (e.g., for research on schizophrenia, at least through the period of early adulthood). Furthermore, theoretically driven biological-genetic and nonbiological-nongenetic information should be collected and these measurements must change as a function of the developmental period being investigated and the questions being posed. In keeping with Sameroff and Chandler's (1975) call for the simultaneous examination of reproductive and caretaking casualty, future work in this area must employ methodological pluralism and strive for fidelity between the current systems theory models of brain-behavior relations and the nature of the methods and measures utilized in studies of neurodevelopment and psychopathology. In the search for discovering the processes linking various developmental pathways to the same psychopathological outcome, study designs should incorporate sufficiently large samples to permit the identification of relatively homogeneous profiles of individuals that can be subjected both to variable-oriented and person-oriented statistical analyses (Cicchetti \& Rogosch, 1997).

Because not all individuals with similar genetic vulnerabilities and caretaking experiences are affected in the same fashion, research in the area of neurodevelopment and psychopathology must incorporate individualdifference analyses into its designs. For example, although a growing body of evidence suggests that maltreatment experiences can impact negatively on brain structure, function, and organization (Cicchetti \& Toth, 1998), it is highly unlikely that the brains of all maltreated children are uniformly affected. Indeed, because some maltreated children function extremely well, even in the presence of adversity (Cicchetti \& Rogosch, 1997), it is conceivable that maltreatment exerts a different impact on neurobiological structure, function, and organization in these children than it does in the typical maltreated child. Future research should ascertain whether the brain structures and function of resilient maltreated children indeed differ from those of their less resilient maltreated counterparts. Similar work on individual differences underlying neurodevelopmental and behavioral outcomes in other high-risk groups of individuals should be conducted.

Research on neurodevelopment and psychopathology also has revealed that some early lesions may not be easily reversible, despite earlier beliefs that brain insults occurring early in ontogenesis were most amenable to reorganization and repair (see, e.g., Cannon, 1998; Keshavan et al., 1994; Lyon et al., 1989; Mednick et al., 1988; Watson et al., 1999; Weinberger, 1987). Conversely, contemporary neurobiological research suggests that in some domains (e.g., sensory, motor, cognitive, and linguistic development) and in some areas of the brain, plasticity is possible, including new neuron generation, well into adulthood. It will be critical to ascertain the mechanisms whereby latent progenitor cells are controlled and glial cell activation, adaptive and maladaptive, is modulated, in order to discover the bases of the brain's self-repair processes (Lowenstein \& Parent, 1999). If scientists can discover the mechanisms whereby neural plasticity may occur in various highrisk conditions and mental disorders, then such information should provide crucial insights for prevention and intervention. Moreover, future research must be conducted to examine the limits of plasticity in the social and emotional domains.

In this regard, it will be important for those providing therapeutic interventions to be cognizant of the fact that the neural and environmental mechanisms responsible for developing a mental disorder may not be the same mechanisms or systems operating in the maintenance of the disorder (cf. Courchesne et al., 1995). Furthermore, prevention research can be conceptualized as true experiments in altering the course of development, thereby providing insight into the etiology and pathogenesis of disordered outcomes. For example, if the developmental course is changed as a result of the implementation of preventive interventions and risk for negative outcomes is reduced, then prevention research helps to elucidate the processes that are involved in the emergence of psychopathology or other 
negative developmental outcomes. Additionally, knowledge of the precursors to psychopathology, such as those identified by Cornblatt et al. (1999) and Walker et al. (1999), may suggest the timing and content of preventive interventions for various high-risk conditions and mental disorders. Finally, it is necessary to conduct investigations that ascertain whether maladaptive neurobiological structures, functions, and organizations are modifiable or are refractory to intervention. There is growing evidence that successful intervention modifies not only maladaptive behavior but also the cellular and physiological correlates

\section{References}

Aglioti, S., Bonazzi, A., \& Cortese, F. (1994). Phantom lower limb as a perceptual marker of neural plasticity in the mature human brain. Proceedings of the Royal Society of London Bulletin, 225, 273-278.

Alberts, B., Bray, D., Lewis, J., Raff, M., Roberts, K., \& Watson, J. D. (1994). Molecular biology of the cell, (3rd ed.). New York: Garland Publishing.

Arnold, S. E. (1999). Neurodevelopmental abnormalities in schizophrenia: Insights from neuropathology. Development and Psychopathology, 11, 439-456.

Benes, F. M. (1995). A neurodevelopmental approach to the understanding of schizophrenia and other mental disorders. In D. Cicchetti \& D. J. Cohen (Eds.), Developmental psychopathology: Vol. 1. Theory and methods (pp. 227-253). New York: John Wiley \& Sons.

Boyce, W. T., Frank, E., Jensen, P., Kessler, R. C., Nelson, C. A., Steinberg, L., and the MacArthur Foundation Research Network on Psychopathology and Development (1998). Social context in developmental psychopathology: Recommendations for future research from the MacArthur Network on Psychopathology and Development. Development and Psychopathology, 10, 143-164.

Bremner, J. D., \& Narayan, M. (1998). The effects of stress on memory and the hippocampus throughout the life cycle: Implications for childhood development and aging. Development and Psychopathology, 10, 871-885.

Breslin, N. A., \& Weinberger, D. R. (1990). Schizophrenia and the normal functional development of the prefrontal cortex. Development and Psychopathology, 2, 409-424.

Brown, J. W. (1994). Morphogenesis and mental process. Development and Psychopathology, 6, 551-563.

Brown, M. A., \& Semelka, R. (1995). MRI: Basic principles and applications. New York: Wiley-Liss.

Cajal, R., \& May, R. (Eds.) (1959). Degeneration and regeneration of the nervous system. New York: Hafner (originally published 1913).

Cannon, T. D. (1996). Abnormalities of brain structure and function in schizophrenia: Implications for etiology and pathophysiology. Annals of Medicine, 28, 533-539.

Cannon, T. D. (1998). Genetic and perinatal influences in the etiology of schizophrenia: A neurodevelopmental of behavior (Eisenberg, 1995; Kandel, 1998, 1999).

In closing, it is our hope that this Special Issue will enhance what we consider to be a potentially rich dialogue between scientists focusing on biological contributors to psychopathology and those immersed in understanding psychological and social factors that are operative in the genesis and maintenance of disorders. We believe that such mutually beneficial interchanges will be transferable to the intervention and social policy arenas, thereby fostering both scientific and applied advances in the field of developmental psychopathology.

model. In M. F. Lenzenweger \& R. H. Dworkin (Eds.), Originals and development of schizophrenia (pp. 67-92). Washington, DC: American Psychological Association.

Cannon, T. D., Mednick, S., Parnas, J., Schulsinger, F., Praestholm, J., \& Vestergaard, A. (1993). Developmental brain abnormalities in the offspring of schizophrenic mothers: I. Contributions of genetic and perinatal factors. Archives of General Psychiatry, 50, 551-564.

Cannon, T. D., Mednick, S. A., Schulsinger, F., Parnas, J., Praestholm, J., \& Vestergaard, A. (1994). Developmental brain abnormalities in the offspring of schizophrenic mothers: II. Structural brain characteristics of schizophrenia and schizotypal personality disorder. Archives of General Psychiatry, 51, 955-962.

Cannon, T. D., Rosso, I. M., Bearden, C. E., Sanchez, L. E., \& Hadley, T. (1999). A prospective cohort study of neurodevelopmental processes in the genesis and epigenesis of schizophrenia. Development and Psychopathology, 11, 467-485.

Cannon, T. D., van Erp, T. G. M., Huttenen, M., Lonnqvist, J., Salonen, O., Valanne, L., Poutanen, V. P., \& Standerskjold-Nordenstam, C. G. (in review). Perinatal hypoxia and regional brain morphology in schizophrenic patients, their siblings, and controls. Archives of General Psychiatry.

Cannon, T. D., van Erp, T. G. M., Huttunen, M., Lonnqvist, J., Salonen, O., Valanne, L., Poutanen, V. P., Standertskjold-Nordenstam, C. G., Gur, R. E., \& Yan, M. (1998). Regional gray matter, white matter, and cerebrospinal fluid distributions in schizophrenic patients, their siblings, and controls. Archives of General Psychiatry, 55, 1084-1091.

Chugani, H., Phelps, M., \& Mazziotta, J. (1987). Position emission tomography study of human brain functional development. Annals of Neurology, 22, 487-497.

Cicchetti, D. (1984). The emergence of developmental psychopathology. Child Development, 55, 1-7.

Cicchetti, D. (1990). A historical perspective on the discipline of developmental psychopathology. In J. Rolf, A. Masten, D. Cicchetti, K. Nuechterlein, \& S. Weintraub (Eds.), Risk and protective factors in the development of psychopathology (pp. 2-28). New York: Cambridge University Press.

Cicchetti, D. (1993). Developmental psychopathology: 
Reactions, reflections, projections. Developmental Review, 13, 471-502.

Cicchetti, D., \& Aber, J. L. (1998). Contextualism and developmental psychopathology. Development and Psychopathology, 10, 137-141.

Cicchetti, D., \& Cohen, D. (Eds.). (1995a). Developmental psychopathology: Vol 1. Theory and method. New York: Wiley.

Cicchetti, D., \& Cohen, D. (Eds.). (1995b) Developmental psychopathology: Vol 2. Risk, disorder, and adaptation. New York: Wiley.

Cicchetti, D., \& Rogosch, F.A. (1996). Equifinality and multifinality in developmental psychopathology. Development and Psychopathology, 8, 597-600.

Cicchetti, D., \& Rogosch, F. A. (1997). The role of selforganization in the promotion of resilience in maltreated children. Development and Psychopathology, 9, 797-815

Cicchetti, D., \& Toth, S. L. (1991). The making of a developmental psychopathologist. In J. H. Cantor, C. C. Spiker, \& L. P. Lipsitt (Eds.), Child behavior and development: Training for diversity (pp. 34-72). Norwood, NJ: Ablex Publishing Corporation.

Cicchetti, D., \& Toth, S.L. (1998). Perspectives on research and practice in developmental psychopathology. In W. Damon (Series Ed.), Handbook of child psychology (5th ed., Vol. 4, pp. 479-583). New York: Wiley.

Cicchetti, D., \& Tucker, D. (1994a). Development and self-regulatory structures of the mind. Development and Psychopathology, 6, 533-549.

Cicchetti, D., \& Tucker, D. (Eds.). (1994b). Neural plasticity, sensitive periods, and psychopathology. Development and Psychopathology, 6, 531-814.

Conel, J. (1939-1967). The postnatal development of the human cerebral cortex (Vols. 1-8). Cambridge, MA: Harvard University Press.

Cornblatt, B., Obuchowski, M., Roberts, S., Pollack, S., \& Erlenmeyer-Kimling, L. (1999). Cognitive and behavioral precursors of schizophrenia. Development and Psychopathology, 11, 487-508.

Courchesne, E., Chisum, H., \& Townsend, J. (1994) Neural activity-dependent brain changes in development: Implications for psychopathology. Development and Psychopathology, 6, 697-722.

Courchesne, E., Townsend, J., \& Chase, C. (1995). Neurodevelopmental principles guide research on developmental psychopathologies. In D. Cicchetti \& D. J. Cohen (Eds.), Developmental psychopathology: Vol. 1. Theory and method (pp. 195-226). New York: Wiley.

Cowan, W., Fawcett, J., O'Leary, D., \& Stanfield, B. (1984). Regressive events in neurogenesis. Science, $225,1258-1265$

Crick, F. (1994). The astonishing hypothesis: The scientific search for the soul. New York: Charles Scribner's Sons.

Damasio, A. R. (1994). Descartes' error: Emotion, reason, and the human brain. New York: Putnam.

Damon, W. (Series Ed.). (1998). Handbook of child psychology (5th ed., Vols. 1-4). New York: Wiley.

Dawson, G., \& Fischer, K. W. (Eds.). (1994). Human behavior and the developing brain. New York: Guilford.

Dawson, G., Frey, K., Self, J., Panagiotides, H., Hessl, D. Yamada, E., \& Rinaldi, J. (1999). Frontal brain electrical activity in infants of depressed and nondepressed mothers: Relation to variations in infant behavior. $D e$ velopment and Psychopathology, 11, 589-605.
Dawson, G., Grofer Klinger, L., Panagiotides, H., Hill, D., \& Spieker, S. (1992). Frontal lobe activity and affective behavior of infants of mothers with depressive symptoms. Child Development, 63, 725-737.

Dawson, G., Hessl, D., \& Frey, K. (1994). Social influences on early developing biological and behavioral systems related to risk for affective disorder. Development and Psychopathology, 6, 759-779.

DeBellis, M. D., Keshavan, M. S., Casey, B. J., Clark, D. B., Giedd, J., Boring, A. M., Frustaci, K., \& Ryan, N. D. (1999). Developmental traumatology: Biological stress systems and brain development in maltreated children with PTSD Part II: The relationship between characteristics of trauma and psychiatric symptoms and adverse brain development in maltreated children and adolescents with PTSD. Biological Psychiatry, 45, 1271-1284.

Dorovini-Zis, K., \& Dolman, C. (1977). Gestational development of brain. Archives of Pathological Laboratory Medicine, 101, 192-195.

Edelman, G. (1987). Neural Darwinism. New York: Basic Books.

Eisenberg, L. (1995). The social construction of the human brain. American Journal of Psychiatry, 152, $1563-1575$.

Erlenmeyer-Kimling, L., Marcuse, Y., Cornblatt, B., Friedman, D., Rainer, J. D., \& Rutschmann, J. (1984). The New York high-risk project. In N. F. Watt, E. J. Anthony, L.C. Wynne, and J. Rolf (Eds.), Children at risk for schizophrenia: A longitudinal perspective (pp. 169-189). New York: Cambridge University Press.

Feinberg, I. (1982). Schizophrenia: Caused by a fault in programmed synaptic elimination during adolescence? Journal of Psychiatry Research, 17, 319-330.

Fish, B. (1977). Neurobiological antecedents of schizophrenia in children: Evidence for an inherited, congenital neurointegrative defect. Archives of General Psychiatry, 34, 1297-1313.

Fish, B., Marcus, J., Hans, S., Auerbach, J., \& Perdue, S. (1992). Infants at risk for schizophrenia. Sequelae of a genetic neurointegrative defect. Archives of General Psychiatry, 49, 221-235.

Fischer, K. W., \& Rose, S.P. (1996). Dynamic growth cycles of brain and cognitive development. In R. W. Thatcher, G. R. Lyon, J. Rumsey, and N. Krasnegor (Eds.), Developmental neuroimaging: Mapping the development of brain and behavior (pp. 263-279). San Diego: Academic Press.

Frackowiak, R., Friston, K., Frith, C., Dolan, R., \& Mazziotta, J. (1997). Human brain function. San Diego: Academic Press.

Gazzaniga, M. (Ed.) (1995). The cognitive neurosciences. Cambridge, MA: MIT Press.

Gillberg, C. (1999). Neurodevelopmental processes and psychological functioning in autism. Development and Psychopathology, 11, 567-587.

Gilman, S. (1998a). Imaging the brain (Part I). The New England Journal of Medicine, 338, 812-820.

Gilman, S. (1998b). Imaging the brain (Part II). The New England Journal of Medicine, 338, 889-896.

Goldman-Rakic, P. (1987). Development of cortical circuitry and cognitive function. Child Development, 58, 601-622.

Gottlieb, G. (1991). Experiential canalization of behavioral development: Theory. Developmental Psychology, 27, 4-13.

Gottlieb, G. (1992). Individual development and evolution: The genesis of novel behavior. New York: Oxford University Press. 
Gottlieb, G., Wahlsten, D., \& Lickliter, R. (1998). The significance of biology for human development: A developmental psychobiological systems view. In W. Damon (Series Ed.) and R. Lerner (Vol. Ed.), Handbook of child psychology: Vol. 1. Theoretical models of human development (pp. 233-273). New York: Wiley.

Gould, E., Tanapat, P., McEwen, B. S., Flugge, G., \& Fuchs, E. (1998). Proliferation of granule cell precursors in the dentate gyrus of adult monkeys is diminished by stress. Proceedings of the National Academy of Sciences, 95, 3168-3171.

Graham, Y. P., Heim, C., Goodman, S. H., Miller, A. H., \& Nemeroff, C. B. (1999). The effects of neonatal stress on brain development: Implications for psychopathology. Development and Psychopathology, 11, $545-565$.

Greenough, W., Black, J., \& Wallace, C. (1987). Experience and brain development. Child Development, 58, 539-559.

Gurvits, T. V., Shenton, M. E., Hokama, H., Ohta, H., Lasko, N. B., Gilbertson, M. W., Orr, S. P., Kikinis, R., Jolesz, F. A., McCarley, R. W., \& Pitman, R. K. (1996). Magnetic resonance imaging study of hippocampal volume in chronic, combat-related posttraumatic stress disorder. Biological Psychiatry, 40, 1091-1099.

Hann, D., Huffman, L., Lederhendler, I., \& Meinecke, D. (Eds.). (1998). Advancing research on develoment plasticity: Integrating the behavioral science and neuroscience of mental health. Bethesda, MD: National Institute of Mental Health.

Huttenlocher, P. R. (1979). Synaptic density in human frontal cortex: Developmental changes and effects of aging. Brain Research, 163, 195-205.

Johnson, M. H. (Ed.). (1993). Brain development and cognition: A Reader. Cambridge, MA: Blackwell.

Johnson, M. H. (1998). The neural basis of cognitive development. In W. Damon (Series Ed.) \& D. Kuhn \& R. Siegler (Vol. Eds.), Handbook of child psychology: Vol. 2. Cognition, perception and language (pp. 149). New York: Wiley.

Johnson, M. H. (1999). Cortical plasticity in normal and abnormal cognitive development: Evidence and working hypotheses. Development and Psychopathology, 11, 419-437.

Jones, N., Field, T., Fox, N., Lundy, B., \& Devalos, M. (1997). EEG activation in 1-month-old infants of depressed mothers. Development and Psychopathology, 9, 491-505.

Kandel, E. R. (1998). A new intellectual framework for psychiatry. American Journal of Psychiatry, 155, 457-469.

Kandel, E. R. (1999). Biology and the future of psychoanalysis: A new intellectual framework for psychiatry revisited. American Journal of Psychiatry, 156, 505-524.

Kempermann, G., Kuhn, H. G., \& Gage, F. (1998). Experience-induced neurogenesis in the senescent dentate gyrus. Society for Neuroscience, 18, 3206-3212.

Keshavan, M. S., Anderson, S., \& Pettegrew, J. W. (1994). Is schizophrenia due to excessive synaptic pruning in the prefrontal cortex? The Feinberg hypothesis revised. Journal of Psychiatric Research, 28, 239-265.

Keshavan, M. S., \& Hogarty, G. E. (1999). Brain maturational processes and delayed onset in schizophrenia. Development and Psychopathology, 11, 525-543.
Keshavan, M. S., \& Murray, R. M. (Eds.). (1997). Neurodevelopment and adult psychopathology. Cambridge: Cambridge University Press.

Kraepelin, E. (1919). Dementia praecox and paraphrenia. Edinburgh, Scotland: Livingston.

Lilienfeld, A. M., \& Parkhurst, E. (1951). A study of the association of factors of pregnancy and parturition with the development of cerebral palsy: A preliminary report. American Journal of Hygiene, 53, 262-282.

Lowenstein, D. H., \& Parent, J. M. (1999). Brain, heal thyself. Science, 283, 1126-1127.

Luthar, S. S., Cicchetti, D., \& Becker, B. (in press). The construct of resilience: A critical evaluation and guidelines for future work. Child Development.

Lyon, M., Barr, C., Cannon, T. D., Mednick, S. A., \& Shore, D. (1989). Fetal neural developmental and schizophrenia. Schizophrenia Bulletin, 15, 149-160.

McEwen, B. S. (1998). Protective and damaging effects of stress mediators. Seminars in Medicine of the Beth Israel Deaconess Medical Center, 338, 171-179.

McEwen, B. S., \& Sapolsky, R. M. (1995). Stress and cognitive function. Current Opinion in Neurobiology, 5, 205-216.

McEwen, B. S., \& Stellar, E. (1993). Stress and the individual: Mechanisms leading to disease. Archives of Internal Medicine, 153, 2093-2101.

McNeil, T. F. (1988). Obstetric factors and perinatal injuries. In M. Tsuang \& J. Simpson (Eds.), Handbook of schizophrenia: Vol. 3. Nosology, epidemiology, and genetics (pp. 319-343). Amsterdam: Elsevier Science.

Meaney, M. J., Aitken, D. H., \& Sapolsky, R. M. (1991). Environmental regulation of the adrenocortical stress response in female rats and its implications for individual differences in aging. Neurobiology of Aging, 12, 31-38.

Mednick, S. A. (1970). Breakdown in individuals at high risk for schizophrenia: Possible predispositional prenatal factors. Mental Hygiene, 54, 50-63.

Mednick, S. A., Cannon, T. D., Barr, C. E., \& LaFosse, J. M. (Eds.). (1991). Developmental neuropathology of schizophrenia. New York: Plenum Press.

Mednick, S. A., Cannon, T. D., Barr, C. E., \& Lyon, M. (Eds.). (1991). Fetal neural development and adult schizophrenia. Cambridge: Cambridge University Press.

Mednick, S. A., \& Hollister, J. M. (Eds.). (1995). Neural development and schizophrenia: Theory and research. New York: Plenum Press.

Mednick, S. A., Machon, R., Huttunen, M., \& Bonett, D. (1988). Adult schizophrenia following prenatal exposure to an influenza epidemic. Archives of General Psychiatry, 45, 189-192.

Meehl, P. E. (1962). Schizotaxia, schizotypy, schizophrenia. American Psychologist, 17, 827-838.

Meehl, P. E. (1989). Schizotaxia revisited. Archives of General Psychiatry, 46, 935-944.

Merzenich, M. M. (1998). Long-term change of mind. Science, 282, 1062-1063.

Merzenich, M. M., Jenkins, W. L., Johnston, P., Schreiner, C., Miller, S., \& Tallal, P. (1996). Temporal processing deficits of language-learning impaired children ameliorated by training. Science, 271, 77-81.

Miller, N. (1995). Clinical-experimental interactions in the development of neuroscience: A primer for nonspecialists and lessons for young scientists. American Psychologist, 50, 901-911. 
Nahas, Z., George, M., Lorberbaum, J., Risch, S. C., \& Spicer, K. (1998, March). SPECT and PET in neuropsychiatry. Primary Psychiatry, pp. 52-59.

Nelson, C. A., \& Bloom, F. E. (1997). Child development and neuroscience. Child Development, 68, 970-987.

Niswader, K. R., \& Gordon, M. (1992). The collaborative perinatal study of the National Institute of Neurological Diseases and Stroke: The women and their pregnancies. Philadelphia: W.B. Saunders.

Nowakowski, R. S. (1987). Basic concepts of CNS development. Child Development, 58, 568-595.

Nowakowski, R. S., \& Hayes, N. L. (1999). CNS development: An overview. Development and Psychopathology, 11, 395-417.

Pasamanick, B., \& Knobloch, H. (1961). Epidemiologic studies on the complications of pregnancy and the birth process. In G. Caplan (Ed.), Prevention of mental disorders in children. New York: Basic Books.

Pennington, B. F. (1999). Towards an integrated understanding of dyslexia: Genetic, neurological, and cognitive mechanisms. Development and Psychopathology, 11, 629-654.

Perry, B., Pollard, R., Blakley, T., Baker, W., \& Vigilante, D. (1995). Childhood trauma, the neurobiology of adaptation, and "Use-Dependent" development of the brain: How "states" become "traits." Infant Mental Health Journal, 16, 271-291.

Pollak, S., Cicchetti, D., Klorman, R., \& Brumaghim, J. (1997). Cognitive brain event-related potential and emotion processing in maltreated children. Child Development, 5, 773-787.

Post, R. M., Weiss, S. R. B., \& Leverich, G. S. (1994). Recurrent affective disorder: Roots in developmental neurobiology and illness progression based on changes in gene expression. Development and Psychopathology, 6, 781-813.

Rakic, P. (1988). Intrinsic and extrinsic determinants of neocortical parcellation: A radial unit model. In P. Rakic and W. Singer (Eds.), Neurobiology of neocortex (pp. 5-27). New York: Wiley.

Rakic, P. (1995). Corticogenesis in human and nonhuman primates. In M. Gazzaniga (Ed.), The cognitive neurosciences (pp. 127-145). Cambridge, MA: MIT Press.

Reese, H., \& Overton, W. (1970). Models of development and theories of development. In L. R. Goulet \& P. Baltes (Eds.), Life span developmental psychology: Research and theory (pp. 115-145). New York: Academic Press.

Sameroff, A., \& Chandler, M. (1975). Reproductive risk and the continuum of caretaking casualty. In F. Horowitz (Ed.) Review of child development research (Vol. 4, pp. 187-244). Chicago: University of Chicago Press.

Sapolsky, R. M. (1992). Stress, the aging brain, and the mechanisms of neuron death. Cambridge, MA: MIT Press.

Segalowitz, S. J. (1994). Developmental psychology and brain development: A historical perspective. In G. Dawson and K. W. Fischer (Eds.), Human behavior and the developing brain (pp. 67-92). New York: Guilford.

Sidman, R. L., \& Rakic, P. (1973). Neuronal migration with special reference to developing human brain: A review. Brain Research, 63, 1-35.

Sidman, R. L., \& Rakic, P. (1982). Development of the human central nervous system. In W. Haymaker \& R. D. Adams (Eds.), Histology and histopathology of the nervous system (pp. 3-145). Springfield, IL: Thomas.

Sur, M., Garraghty, P. E., \& Roe, A. W. (1988). Experimentally induced visual projections into auditory thalamus and cortex. Science, 242, 1437-1441.

Sur, M., Pallas, S. L., \& Roe, A. W. (1990). Cross-modal plasticity in cortical development: Differentiation and specification of sensory neocortex. Trends in Neuroscience, 13, 227-233.

Sutcliffe, J., Milner, R., Gottesfeld, J., \& Reynolds, W. (1984). Control of neuronal gene expression. Science, 225, 1308-1315.

Tallal, P., Miller, S. L., Bedi, G., Byma, G., Wang, X., Nagarajan, S. S., Schreiner, C., Jenkins, W. M., \& Merzenich, M. M. (1996). Language comprehension in language-learning impaired children improved with acoustically modified speech. Science, 271, 81-84.

Taylor, E. (1999). Developmental neuropsychopathology of attention deficit and impulsiveness. Development and Psychopathology, 11, 607-628.

Thatcher, R. W., Hallett, M., Zeffiro, T., John, E. R., \& Huerta, M. (Eds.) (1994). Functional neuroimaging: Technical foundations. San Diego: Academic Press.

Thatcher, R. W., Lyon, G. R., Rumsey, J., \& Krasnegor, N. (Eds.). (1996). Developmental neuroimaging: Mapping the development of brain and behavior. San Diego: Academic Press.

Thelen, E., \& Smith, L. B. (1994). A dynamic systems approach to the development of cognition and action. Cambridge, MA: MIT Press.

Thelen, E., \& Smith, L. B. (1998). Dynamic systems theories. In W. Damon (Series Ed.) and R. Lerner (Vol. Ed.) Handbook of child psychology: Volume 1. Theoretical models of human development (pp. 563-634). New York: Wiley.

Toga, A., \& Mazziotta, J. (Eds.). (1996). Brain mapping: The methods. San Diego: Academic Press.

Waddington, C. H. (1957). The strategy of genes. London: Allen and Unwin.

Walker, E. F., Lewis, N., Loewy, R., \& Palyo, S. (1999). Motor dysfunction and risk for schizophrenia. Development and Psychopathology, 11, 509-523.

Walker, E. F., Savoie, T., \& Davis, D. (1994). Neuromotor precursors of schizophrenia. Schizophrenia Bulletin, 20, 453-480.

Watson, J. B., Mednick, S. A., Huttunen, M., \& Wang, X. (1999). Prenatal teratogens and the development of adult mental illness. Development and Psychopathology, 11, 457-466.

Weinberger, D. R. (1987). Implications of normal brain development for the pathogenesis of schizophrenia. Archives of General Psychiatry, 44, 660-669.

Weinberger, D. R. (1995). From neuropathology to neurodevelopment. Lancet, 346, 552-557.

Weiss, P. (1959). Cellular dynamics. Review of Modern Physics, 31, 11-20.

Weiss, P. (1969). Principles of development. New York: Hafner. 